\title{
IN their words
}

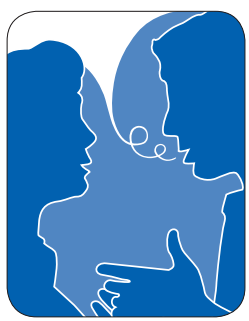

"It could very well transform Google into another type of company-it partners with a pharmaceutical company or licenses its discoveries and patents its discoveries." George Geis, UCLA Anderson School of Management, sees Google's foray

into genomics as a potentially lucrative move. (SFGate, 18 March 2014)

"It may all go well, but in other cases there will be surprises - and you don't really want surprises with genetic data." Lee Tien, a lawyer with the Electronic Frontier Foundation of San Francisco, also speaking of Google's invitation to geneticists to upload information in its cloud. (SFGate, 18 March 2014)
"The FDA bureaucracy has become so cumbersome and so demanding that hardly any inexpensive drug or drug aimed at a small market can overcome the cost of getting through the process." Newt Gingrich blogs about the FDA, recommending replacing it rather than reforming it. (Gingrich Productions, 26 March 2014)

"If a pen or a $\$ 150$ dinner presents a conflict for a doctor, what does it mean if you get $\$ 300,000$ ?" Walid Gellad of the VA Pittsburgh Healthcare System and co-author of a recent study of the participation of academic physicians on drug company boards, which found that the average compensation from drug companies was $\$ 313,000$. (Milwaukee Journal Sentinel, 1 April 2014)

"The fear that Congress may begin a program of meddling, one drug at a time, doesn't affect just one drug. It kind of scares everyone." Andrew A. Bogan of Bogan Associates, which invests in science and technology stocks, on the high price of Gilead's hepatitis C drug Sovaldi, which sells for $\$ 1,000$ per pill. (The New York Times, 21 March 2014)

"There was a warm reception in London." Circassia's CEO Steven Harris, as his company takes in \$332 million in its London stock exchange debut. The company has a cat allergy product in phase 3 clinical trials. (Reuters, 13 March 2014)

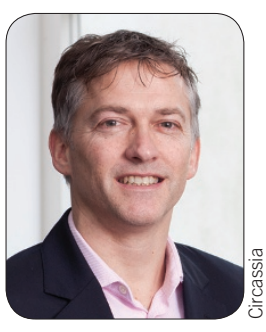

Circassia CEO Steven Harris

\section{Around the world in a month}

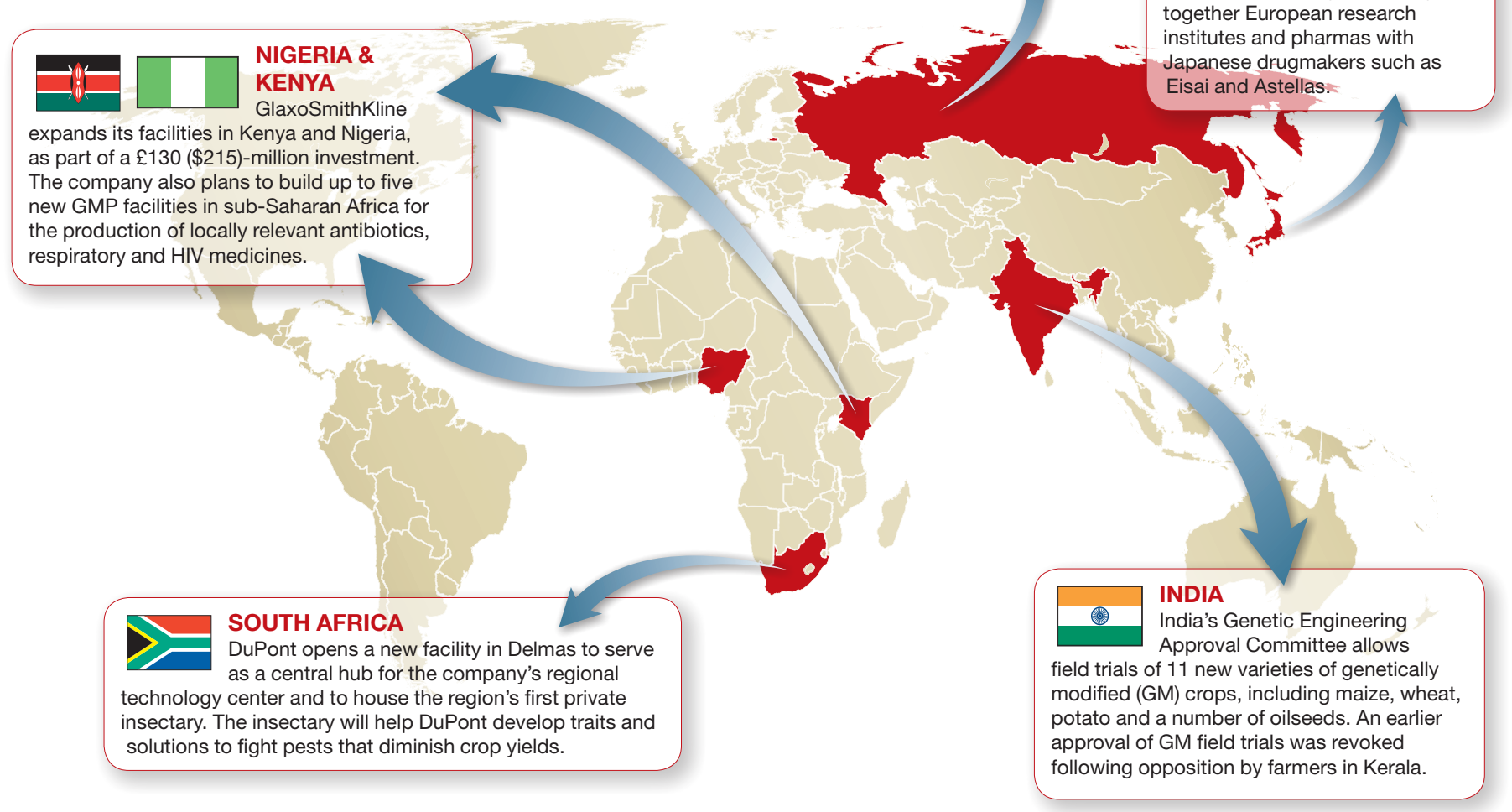

\section{RUSSIA}

Russia rejects imports of genetically modified organisms (GMOs).

Prime Minister Dmitry Medvedev said that the country has enough space and resources to produce organic food. In February, the Russian Parliament called for a ban on the registration and trade of GMOs until a working regulatory system is in place.

\section{JAPAN \\ A new Japanese public health} partnership, The Global Health Innovative Technology Fund, awards \$12 million to speed the development of treatments for some of the world's most neglected diseases including Chagas disease, schistosomiasis, parasitic roundworms and tuberculosis. The grants bring together European research institutes and pharmas with Japanese drugmakers such as Eisai and Astellas. respiratory and HIV medicines. 